\title{
Predisposing risk factors for community-associated methicillin-resistant staphylococcus aureus infection: a study in a teaching hospital
}

\begin{abstract}
The recent appearance of Community-Acquired Methicillin-resistant Staphylococcus aureus (CA-MRSA) infection in the context of ambulatory care and outpatient clinics in large metropolitan areas over all the world has attracted considerable interest from researchers in assessing the related epidemiological profiles. The present study aimed to identify potential predisposing risk factors of CA-MRSA infection using a case-control design. The epidemiological variables of patients diagnosed with CAMRSA infection were compared to healthy controls. Data were collected from medical records and following univariate, logistic regression and forest plot calculation were performed. Smoking, HIV, trauma, congestive heart failure, recreational drugs, tattooing were potentially associated with an increased risk of community-associated MRSA predisposition. Dyslipidemia, diabetes mellitus and vascular catheter carriers were potentially associated with a risk of moderate predisposition while atopy, practice of sports, recent use of antibiotics was associated with no risk of CA-MRSA infection. Hypertension and COPD were possible protective factors. Although the study of predisposing risk factors for the CA-MRSA infection is promising, future clinical epidemiological studies including new strategies are recommended to better standardize predisposing risk factors and to control to spurious associations.
\end{abstract}

Keywords: staphylococcal infection, methicillin resistant staphylococcus aureus, Risk factors
Special Issue - 2018

\section{Caroline Bozzetto Ambrosi \\ Specialist in Family Medicine and Resident in Internal Medicine, Brazil}

Correspondence: Caroline Bozzetto Ambrosi, Specialist in Family Medicine, Resident in Internal Medicine, Hospital Moinhos de Vento, Porto Alegre, Brazil, Email caroline.ambrosi@outlook.com

Received: September 09, 2017 | Published: September 27, 2018

\section{Introduction}

Community-acquired (CA) Methicillin-resistant Staphylococcus aureus (MRSA) infections occurs among healthy people or individuals with no identifiable healthcare-related predisposing risk factors. Communities all over the world with social and material deprivation have been significantly affected by the emergence of the condition since the end of the 20th century. ${ }^{1-7}$ While the first documented cases of CA-MRSA infections occurred among Australian and Canadian aborigines in the early 1990s, infections that sharing the same genetical features than these first cases spread throughout the world. Particularly, in Brazil, the first report of CA-MRSA was similar to the Oceanian clones: two young individuals (23-year-old male and 34 -year-old female who presented respectively skin- and soft tissueassociated infections, and a male, 56years old, presenting with septic arthritis were first documented who came from a city in the south of the country Porto Alegre). ${ }^{8}$ Currently, CA-MRSA infections are increasing within outcare departments in large metropolitan cities. ${ }^{1,7,9-11}$

Based in recent evidence, CA-MRSA infections usually involve cellulitis in skin and soft tissues and abscesses in an estimated $90 \%$ of cases, but isolates of MRSA might lead to more severe infections, such as necrotizing pneumonia and fasciitis, meningitis, bacteraemia and septic shock. ${ }^{3,9,10-15}$ The virulence of CA-MRSA is higher than that of HA-MRSA, as confirmed by comparison of the expression of virulence genes and disease severity in animal infection models. ${ }^{16}$ Regarding the epidemiology, however, unfortunately little is known outside of acute healthcare settings. The isolates of CA-MRSA have different phenotypical and genetic features when compared to HA-
MRSA (healthcare- acquired methicillin-resistant Staphylococcus aureus (HA-MRSA). ${ }^{14-16}$

Interestingly, in contrast to HA-MRSA (healthcare- acquired methicillin-resistant Staphylococcus aureus (HA-MRSA) multifactorial causes are thought to be related with Ca-MRSA and commonly predisposing observed risk factors are associated with community and host determinants of health as physical crowding, poor hygiene, homeless shelters, subsidized housing, absence of in-home water service, time spent at daycare centers (children), household contact with a confirmed case or participation in contact sports; other at-risk groups include tattoo recipients, pregnant and postpartum women, children mainly healthy newborns, military recruits, jail detainees, HIV-infected people and drug users. ${ }^{5}$ As CA-MRSA risk factors infection appear to be varied and closely associated with social and host determinants of health studies based on predisposing risk factors are lacking. The aim of the present study is to identify and evaluate potential predisposing risk factors in a case-control study performed in a teaching hospital of Porto Alegre, Brazil.

\section{Methods}

\section{Study design and population}

Following the institutional review board approval, the casecontrol study was performed within the Clinical Medicine Residency Program of Hospital Restinga Extremo Sul (HRES)- Institute of Education and Research of Hospital Moinhos de Vento, Porto AlegreRS, Brazil according to ethical rules involving human beings. The hospital was created with the Program of Support to the Institutional Development of the Brazilian Health System (PROADI-SUS) and 
started the activities from 1st of July 2014. The HRES catchment area included Restinga and its neighbour's areas of Lami, Lajeado, Belem Velho, Ponta Grossa, Gloria, Hipica, Lombo do Pinheiro, Teresopolis and Chapeu do Sul. According to Figure 1 adapted from the Brazilian Institute of Geography and Statistics (IBGE) and the representative map of neighbours of Porto Alegre by Procempa (Porto Alegre data processing company), the Restinga and its neighbour's area represent one of biggest and most populated portion of Porto Alegre. ${ }^{18,19}$ HRES is a teaching public hospital that covers Adult, Pediatric and Medical Specialties with a Diagnostic Center. ${ }^{17}$ Our study data collection was conducted through a review of the medical records between September 2015 and June 2017. Patients were identified if they were classified in the database as having a positive culture for CA-MRSA. Data collection was conducted through a review of the medical records between September 2015 and June 2017. Patients were identified if they were classified in the database as having a positive culture for CA-MRSA and were followed in the Infectology out Clinic Care. Only patients with more than 18 years old were considered. Two controls were selected from the database for each case and matched by gender and age. The controls patients were those admitted in the HRES for medical reasons other than CA-MRSA. The exclusion criteria were patients less than 18 years old, incomplete information in the medical records, inconclusive diagnosis, laboratory studies on confirmative, history of surgery or hospitalization or dialysis or hospital stay in the last 12 months.

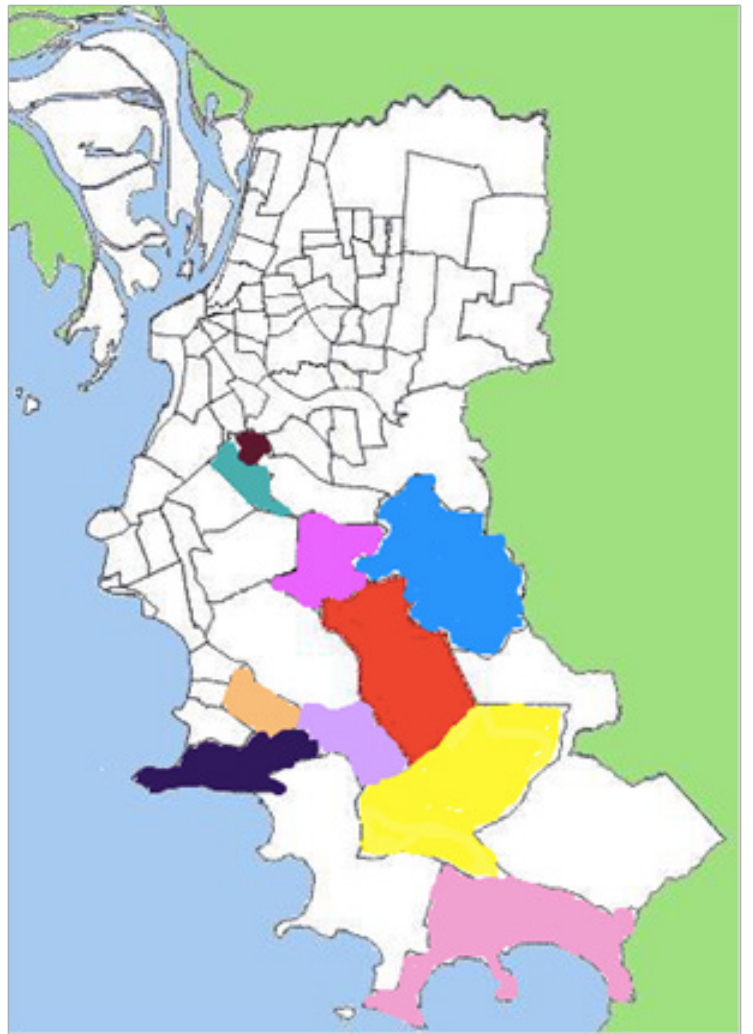

Figure I Adaptation of Restinga and neighbour areas from Procempa to CA MRSA epidemiology.

Legend: Restinga (red), Lageado (yellow), Lomba do Pinheiro (blue), Belém Velho (pink), Chapéu do Sol (light purple), Ponta Grossa (purple), Hípica (Orange), Lami (light pink), Teresópolis (green), Glória (brown)
Information about demographical, socioeconomic and clinical predisposing risk factors/groups were obtained from electronic patient charts of HRES. Data was obtained until patient discharge or ambulatory check-ups. The following demographic factors were studied (sex, age, origin, kind of home [homeless shelters, subsidized housing, absence of in-home water service]); socioeconomic factors (employment, education, smoking, use of alcohol, use of recreative drugs use, sport activities); healthcare-related factors (HIV, hypertension, diabetes mellitus, rheumatic arthritis, dyslipidemia, hepatitis $\mathrm{C}$, cirrhosis, renal failure, COPD, Congestive Heart Failure, metastatic and non metastatic neoplasia, sepsis); use of medications (antibiotics, devices, corticoid, immunosuppressor), infective focus (laboratory analysis), chief complaint, recent trauma history (related with focus).

\section{Statistical analysis}

Descriptive statistics was used to obtain absolute and perceptual distribution to nominal variables and statistical measures were employed to check numerical variables. The Student's t-test or MannWhitney test was used to two independent groups depending on the type of distribution, and chi-square test when indicated. Odds ratios (OR) and their $95 \%$ CIs were computed. The statistical significance was $5 \%(\mathrm{p}=0.05)$. The data were worked in excel worksheet and statistical calculation was worked by Statistical Analysis System version 24.0. The data are shown as mean \pm SD. Statistical forest plot was worked in MedCalc Statistical Software version 16.4.3 (MedCalc Software bvba, Ostend, Belgium).

\section{Results}

Table 1 demonstrated the demographics, socioeconomic and clinical findings of patients with diagnosis of CA-MRSA and controls. We identified eight patients diagnosed with CA-MRSA; however, two cases in patients with less than 18years were excluded from final analysis. No cases of invasive infection were described. From the six cases analysed, three $(50 \%)$ patients were female. The mean age was $46.8 \pm 10.9$ years. Fourteen controls were matched by age and gender; seven patients were female; their mean age was $43.0 \pm 17.85$ years. Between the six cases, 4/6(66.6) were from Restinga and two cases were from Hipica. The controls were originated from Restinga in 71.4 of cases (10/14), 2 cases from Ponta Grossa (14.3\%) and one case from Belem Novo and another one from Teresopolis. The information regarding the homeless shelters, subsidized housing, the absence of in-home water service, unfortunately, were not available in the patient and medical records. All six cases were employed being: 1 case- self-employed, one case- housewife, one case retired. The three others were employed in the Services Sector. Regarding seven controls, three were self-employed, one retired, four housewives, five employed in the Services Sector and one unemployed. Five cases and 12 controls hold the primary education level while only one case and two controls hold the secondary education level. Five patients(83.3) were smokers and one was recreational user drugs, two controls were smokers and one was alcohol user. Two control practised sports. One case and one healthy control had tattoos. There were $2 / 6(33 \%)$ patients with HIV. Seven controls had hypertension and 2/6(33.3) cases and 2/14(14.3) had diabetes mellitus diabetes. One patient had heart failure. Three (21.4) controls had COPD. One patient and one control undertook antibiotic recently. One patient and one control had vascular devices. One patient and two control had atopy. One control used immunosuppressor. Two cases and one control had dyslipidemia. 
Table I Demographic characteristics, socioeconomical and clinical variables of cases and controls

\begin{tabular}{llll}
\hline & Cases $\mathbf{n}=\mathbf{6}$ & Controls $\mathbf{n}=1 \mathbf{4}$ & P Value \\
\hline $\begin{array}{l}\text { Age(yrs) All } \\
\text { Gender }\end{array}$ & $46.83+-10.09$ & $43.00+-17.85$ & \\
Female & $3(50)$ & $7(50)$ & - \\
Male & $3(50)$ & $7(50)$ & - \\
Home & & &
\end{tabular}

$\begin{array}{llll}\text { Restinga } & 4(66.6) & \mathrm{I}(0(7 \mid .4) & \mathrm{P}=0.8315 \\ \text { Ponta Grossa } & - & 2(14.3) & \mathrm{P}=0.8315 \\ \text { Belém Velho } & - & \mathrm{I}(7.1) & \mathrm{P}=0.8315 \\ \text { Hípica } & 2(33.3) & - & \mathrm{P}=0.8315 \\ \text { Teresópolis } & - & \mathrm{I}(7.1) & \mathrm{P}=0.8315\end{array}$

Employment

Retirement I(I6.7)

Housewife

$4(28.5)$

Unemployment $-$

Others

3(49.9)

5(35.7)

Education

Primary

12(85.7)

Secondary

Recreational

Smoking

Alcohol

Drugs

Sports

Tattoo

Healthcare

HIV

Hypertension

DM

RA

Dyslypidemia

2(33.3)

Hepatitis C

COPD

$\mathrm{CHF}$

Metastatic

Neoplasia

ATB

-

-

I (16.7)

-

I(16.7)

Vascular Devices

I (16.7)

Imunossupressor

I(I6.7)

Atopia

I(I6.7)
2(14.3)

$-$

7(50)

2(14.3)

I(7.I)

2(14.3)

I (7.I)

$3(21.4)$

-

I (7.I)

2(14.3)

I (7.I)

I(7.I)

2(14.3)
$\mathrm{P}=0.0902$

$\mathrm{P}=0.4958$

$\mathrm{P}=0.3414$

$\mathrm{P}=0.8289$

$\mathrm{P}=0.34 \mid 4$

$\mathrm{P}=0.8289$

$\mathrm{P}=0.3869$

$\mathrm{P}=0.2260$

$\mathrm{P}=0.8289$

$\mathrm{P}=0.8914$

$\mathrm{P}=0.5266$

$\mathrm{P}=0.8289$

$\mathrm{P}=0.8914$

$\mathrm{P}=0.2260$
As illustrated in (Table 1), the two groups, cases and controls, were compared, there were significant statistical differences $(p<0.05)$ with respect to Smoking, HIV, history of recent trauma, congestive heart failure, drugs users and tattoo. Dyslipidemia, DM and vascular devices showed moderate statistical differences. Atopy and use of antibiotics showed low statistical differences. Educations, use of alcohol, sports, rheumatic arthritis, hepatitis C, metastatic neoplasia, immunosuppressor show no statistical differences. Following univariate analysis and logistic regression of identified risk factors predictors: smoking (OR 30, 95\% CI 2.18-411.00); HIV (OR 16, 95\% CI 0.55-303.68); trauma and heart failure on admission and use of drugs (OR 7.99, 95\% CI 0.26-224.93), Tattoo (OR 5.14, 95\% 0.3966.15). Dyslipidemia, DM and vascular devices showed moderate statistical differences. Atopy (OR 1.2, CI 0.08-16.44) and use of antibiotics (OR 1.2, CI 0.08-16.44) showed no statistical differences. Hypertension (OR 0.5, CI 0.06-3.67) and COPD (OR 0.25 CI 0.015.56) were associated with a reduced risk of CA-MRSA infection (Table 2) (Graph 1).

Table 2 Analysis logistic regression of risk groups/factors

\begin{tabular}{lllll}
\hline & $\mathbf{P}$ & $\mathbf{Z}$ & $\mathbf{O R}$ & $\mathbf{9 5 \%} \mathbf{C l}$ \\
\hline COPD & $\mathrm{P}=0.3869$ & 0.865 & 0.5 & $0.0 \mathrm{I}$ to 5.670 \\
Hypertension & $\mathrm{P}=0.4958$ & $0.68 \mathrm{I}$ & 0.5 & 0.0680 to 3.6750 \\
ATB & $\mathrm{P}=0.89 \mathrm{I} 4$ & 0.137 & $\mathrm{I} .2$ & 0.0876 to $\mathrm{I} 6.4403$ \\
Atopy & $\mathrm{P}=0.89 \mathrm{I} 4$ & 0.137 & $\mathrm{I} .2$ & 0.0876 to $\mathrm{I} 6.4403$ \\
Vascular Device & $\mathrm{P}=0.5266$ & 0.633 & 2.6 & $0.135 \mathrm{I}$ to $50.05 \mathrm{I} 3$ \\
DM & $\mathrm{P}=0.34 \mathrm{I} 4$ & $0.95 \mathrm{I}$ & 3 & $0.3 \mathrm{I} 20$ to $28.84 \mathrm{I}$ \\
Dyslipidemia & $\mathrm{P}=0.34 \mathrm{I}$ & $0.95 \mathrm{I}$ & 3 & $0.3 \mathrm{I} 20$ to $28.84 \mathrm{I}$ \\
Tattoo & $\mathrm{P}=0.2089$ & $\mathrm{I} .257$ & 5.1429 & 0.3998 to $66.15 \mathrm{I} 2$ \\
Drugs & $\mathrm{P}=0.2260$ & $\mathrm{I} .2 \mathrm{II}$ & $7.909 \mathrm{I}$ & $0.278 \mathrm{I}$ to 224.9324 \\
CHF & $\mathrm{P}=0.2260$ & $\mathrm{I} .2 \mathrm{II}$ & $7.909 \mathrm{I}$ & $0.278 \mathrm{I}$ to 224.9324 \\
Trauma & $\mathrm{P}=0.2260$ & $\mathrm{I} .2 \mathrm{II}$ & $7.909 \mathrm{I}$ & $0.278 \mathrm{I}$ to 224.9324 \\
HIV & $\mathrm{P}=0.0902$ & $\mathrm{I} .694$ & $\mathrm{I} 6.1 \mathrm{III}$ & 0.5565 to 303.6848 \\
Smoking & $\mathrm{P}=0.0109$ & 2.547 & 30 & 2.1897 to $4 \mathrm{II} .0073$ \\
\hline
\end{tabular}

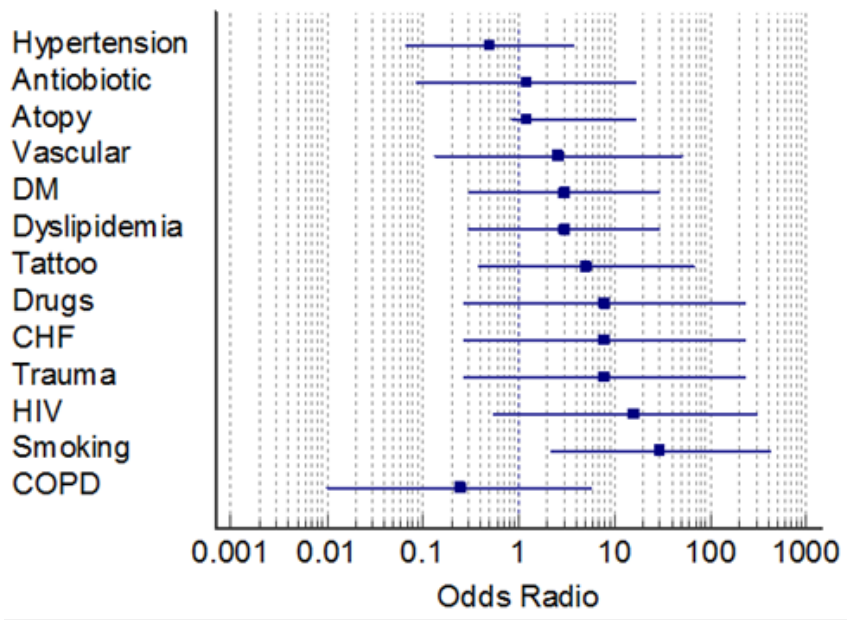

Graph I *Logistic regression of variable including all parameters with $\mathrm{p}<0.05$ in univariate analysis. 


\section{Discussion}

The study provided a comparison of a clinically infected versus a non-infected CA-MRSA population in a teaching hospital in Porto Alegre, RS, Brazil. To our knowledge, this was the first study to correlate predisposing risk factors to CA-MRSA infections based on a study of epidemiological profiles of patients with a diagnosis of CAMRSA infection versus patients admitted for other reasons than CAMRSA. The recognition of potential risk factors associated with this infection will allow the detection, prevention and adoption of measures of CA-MRSA control and improvement of the effectiveness of current treatment. ${ }^{1,3-6,9-11,14,20-25}$ Most of the studies in the literature about the epidemiological profile of individuals affected by CA-MRSA infection described an association of CA-MRSA with factors related to social and material deprivation. ${ }^{1,9,7}$ Presumably, CA-MRSA is transmitted in crowded, homelessness and poor hygiene environment through lack of personal and household care, overpopulation and inadequate sanitary facilities. In addition, factors related to host immunity would likely increase the vulnerability to the infection by modulation the immune response together with a portal of entry (local skin disease or local trauma and injection drug use). ${ }^{1,9}$ Our study showed a potential correlation among smoking, HIV, local trauma, use of recreational drugs and tattooing with Ca-MRSA infection supporting studies that described an association with CA-MRSA and factors related to social and material deprivation as described. Therefore, the exact social and material deprivation epidemiology of the residents (cases and controls) as the state of subsidized housing, the absence of water and sewage in the domicile between cases and controls could not be completely studied due to the nature of the data collection.

Comorbities, as congestive heart failure is relatively uncommon related to CA-MRSA and to our best of knowledge, was firstly reported in the literature. Previous reports are related to infective endocarditis and end-stage renal. Evidence showed a strong association between the high percentage of housing with social and material deprivation with the presence of other risk factors such as black ethnicity, lack of medical and hospital care. Several studies showed that social disadvantage minority populations have higher rates of CA-MRSA infection including African Americans, Canadian First Nation communities, indigenous populations of Australia and New Zealand and jailed prisons in US..$^{1,10,12,20,25}$ Interestingly, we found COPD and hypertension that were potential protective factors. This study used the epidemiological profile of infected and non infected patients within in a teaching hospital. This helped to determinate the risk factors in this particular community setting. Firstly its retrospective nature of data collection included a possible lack of some important data recorded in the charts particularly regarding the social and material deprivation and detailed host related investigation. Studies based on clinical epidemiology and susceptibility are considered to be limited

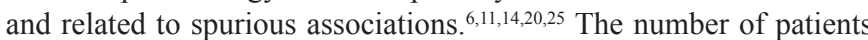
with CA-MRSA was small and also two patients above 18years were excluded. Future studies increased sample and including a population above 18years (as CA-MRSA is prevalent in children and newborns) and additional information measuring material and social deprivation should provide more precise epidemiology to transmission to CAMRSA. Molecular typing studies should be associated as well.

\section{Conclusion}

Over the past few decades, the CA-MRSA-related infection has increased globally and its prevalence continues to escalate the risk with spreading of CA-MRSA within the community possibly due to lack of control of risk factors. Our article based in clinical epidemiology and susceptibility suggested that Smoking, HIV, history of trauma, congestive heart failure, drug users were potential predisposing risk factors for CA-MRSA infection when compared cases and healthy controls. Future prospective studies by exploring the details of host-related factors and measuring the degree of social and material deprivation associated with molecular epidemiology might be important to better determine the susceptibility to CA-MRSA. This information might be important to allow that new strategy can be implemented to reduce risk between in the context of CA-MRSA.

\section{Acknowledgements}

None.

\section{Conflict of interest}

The author declares no conflict of interest.

\section{References}

1. Loewen K, Schreiber Y, Kirlew M, et al. Community-associated methicillin-resistant Staphylococcus aureus infection:Literature review and clinical update. Can Fam Physician. 2017;63(7):512-520.

2. Ribeiro A, Coronado AZ, Silva-Carvalho MC, et al. Detection and characterization of international community-acquired infections by methicillin-resistant Staphylococcus aureus clones in Rio de Janeiro and Porto Alegre cities causing both community- and hospital-associated diseases. Diagn Microbiol Infect Dis. 2007;59(3):339-345.

3. Chambers HF. Community-associated MRSA-resistance and virulence converge. N Engl J Med. 2005;352(14):1485-1487.

4. Dukic VM, Lauderdale DS, Wilder J, et al. Epidemics of communityassociated methicillin-resistant Staphylococcus aureus in the United States:a meta-analysis. Plos One. 2013;8(1):e52722-e52722.

5. Mediavilla JR, Chen L, Mathema B, et al. Global epidemiology of community-associated methicillin resistant Staphylococcus aureus (CAMRSA). Curr Opin Microbiol. 2012;15(5):588-595.

6. De Miranda OP, Silva-Carvalho MC, Ribeiro A, et al. Emergence in Brazil of methicillin-resistant Staphylococcus aureus isolates carrying SCCmecIV that are related genetically to the USA800 clone. Clin Microbiol Infect. 2007;13(12):1165-1172.

7. Tosas Auguet O, Betley JR, Stabler RA, et al. Evidence for Community Transmission of Community-Associated but Not Health-CareAssociated Methicillin-Resistant Staphylococcus Aureus Strains Linked to Social and Material Deprivation:Spatial Analysis of Cross-sectional Data. Plos Medicine. 2016;13(1):e1001944-e1001944.

8. Ribeiro A, Dias C, Silva-Carvalho MC, et al. First report of infection with community-acquired methicillin-resistant Staphylococcus aureus in South America. J Clin Microbiol. 2005;43(4):1985-1988.

9. Evangelista Sde S, de Oliveira AC. Community-acquired methicillinresistant Staphylococcus aureus:a global problem. Rev Bras Enferm. 2015;68(1):128-135. 
10. Wallin TR, Hern HG, Frazee BW. Community-associated methicillinresistant Staphylococcus aureus. Emerg Med Clin North Am. 2008;26(2):431-455.

11. Silva-Carvalho MC, Bonelli RR, Souza RR, et al. Emergence of multiresistant variants of the community-acquired methicillin-resistant Staphylococcus aureus lineage ST1-SCCmecIV in 2 hospitals in Rio de Janeiro, Brazil. Diagn Microbiol Infect Dis. 2009;65(3):300-305.

12. Pannaraj PS, Hulten KG, Gonzalez BE, et al. Infective pyomyositis and myositis in children in the era of community-acquired, methicillin-resistant Staphylococcus aureus infection. Clin Infect Dis. 2006;43(8):953-960.

13. Gelatti LC, Sukiennik T, Becker AP, et al. Sepsis due to communityacquired methicillin-resistant Staphylococcus aureus in southern Brazil. Rev Soc Bras Med Trop. 2009;42(4):458-460.

14. Diep BA, Otto M. The role of virulence determinants in communityassociated MRSA pathogenesis. Trends Microbiol. 2008;16(8):1-369.

15. Gelatti LC, Bonamigo RR, Becker AP, et al. Methicillin-resistant Staphylococcus aureus:emerging community dissemination. An Bras Dermatol. 2009;84(5):501-506.

16. Li S, Li J, Qiao Y, et al. Prevalence and invasiveness of communityacquired methicillin-resistant Staphylococcus aureus:A meta-analysis. Indian J Pathol Microbiol. 2014;57(3):418-114.

17. .https://pt.wikipedia.org/wiki/Restinga_(Porto_Alegre)

18. http://1proweb.procempa.com.br/pmpa/prefpoa/spm/usu_doc/eanteprojeto_de_lei_bairros_2013.pdf
19. http://portalrestinga.com.br/capa/index.php?option=com content\&view $=$ article\&id $=73 \&$ Itemid $=134$

20. Braun T, Kahanov L, Dannelly K, et al. CA-MRSA Infection Incidence and Care in High School and Intercollegiate Athletics. Med Sci Sports Exerc. 2016;48(8):1530-1538.

21. Chuang Y, Huang Y. Molecular epidemiology of community-associated meticillin-resistant Staphylococcus aureus in Asia. Lancet Infect Dis. 2013;13(8):698-708.

22. Gelatti LC, Bonamigo RR, Inoue FM, et al. Community-acquired methicillin-resistant Staphylococcus aureus carrying SCCmec type IV in southern Brazil. Revista da Sociedade Brasileira de Medicina Tropical. 2013;46(1):34-38.

23. Malachowa N, Kobayashi SD, DeLeo FR. Community-associated methicillin-resistant Staphylococcus aureus and athletes. Phys Sportsmed. 2012;40(2):13-21.

24. Maree CL, Eells SJ, Tan J, et al. Risk factors for infection and colonization with community-associated methicillin-resistant Staphylococcus aureus in the Los Angeles County jail:a case-control study. Clin Infect Dis. 2010;51(11):1248-1257.

25. Wang H, Huang C, Huang Y. Clinical features and molecular characteristics of childhood community-associated methicillin-resistant Staphylococcus aureus infection in a medical center in northern Taiwan, 2012. BMC Infect Dis. 2017;17 (1):470. 